\title{
JOHN DUNN
}

\section{A survey of methadone prescribing at an inner-city drug service and a comparison with national data}

\author{
AIMS AND METHOD \\ Surveys suggest that UK drug services \\ under-prescribe methadone to \\ opiate-dependent patients. This \\ study investigated methadone \\ prescribing for 169 patients on \\ long-term methadone at a specialist \\ drug service. \\ RESULTS \\ The mean methadone dose for \\ patients on maintenance was $65.8 \mathrm{mg}$,
}

\author{
and $67.7 \%$ were taking $50 \mathrm{mg}$ or \\ more. Mean doses in relation to \\ methadone formulation varied \\ substantially: mixture $57.4 \mathrm{mg}$, \\ tablets $81.8 \mathrm{mg}$ and ampoules \\ $113.0 \mathrm{mg}$. These figures are higher \\ than those reported from national \\ surveys. The proportion of urine \\ screens positive for illicit opiates was \\ inversely related both to methadone \\ dose and length of time in treatment.
}

\author{
CLINICAL IMPLICATIONS \\ This survey shows the levels of \\ methadone prescribing at an inner- \\ city drug service and gives support to \\ the effectiveness of high-dose \\ methadone maintenance.
}

In 1996, the Department of Health published a review of drug services in England (Department of Health, 1996) and stated that for patients on methadone maintenance, daily doses of over $50 \mathrm{mg}$ were associated with lower rates of heroin use. International research supports this assertion, with results showing that patients on higher doses have better outcomes (Farrell et al, 1994).

Community pharmacy surveys of methadone prescribing in the UK show that over $50 \%$ of patients receive daily doses lower than $50 \mathrm{mg}$ (Strang et al, 1996; Strang \& Sheridan, 1998; Strang \& Sheridan, 2001), with the mean dose being $49 \mathrm{mg}$. In the National Treatment Outcome Research Study, the mean methadone dose prescribed by specialist drug services in the UK was $48 \mathrm{mg}$ (Gossop et al, 1999). These findings have led to concerns that specialist services are under-treating opiate-dependent patients.

A limitation of the pharmacy surveys is that patients in receipt of two prescriptions for different formulations of methadone, such as ampoules and mixture, are counted twice. Furthermore, patients on detoxification programmes, slow reduction regimens and methadone maintenance are grouped together, thus skewing the results to the left. The aim of this study was to audit long-term methadone prescribing at an inner-city, specialist NHS drug service and to compare the results with national data.

\section{The study}

This study was performed over 2 weeks, from 15.7 .02 to 26.7.02.

\section{The service}

The North Camden Drug Service covers the northern half of the London borough of Camden (population 101,700 and Jarman index=32.9). Although there are areas of affluence (e.g. Hampstead Village), it has pockets of deprivation (e.g. Gospel Oak, Camden Town and Kentish Town). Camden \& Islington have the fourth-highest number of drug users notified to the Regional Drug Misuse Database in the whole Thames Region (Department of Health, 1998).

The following on-site treatment services are available: out-patient detoxification, long-term prescribing, keyworking, psychological therapies, psychiatric and medical interventions, an alcohol programme, a crack cocaine programme, needle exchange, hepatitis testing and vaccination, alternative therapies and benefits advice. There is an on-site pharmacy and prescriptions are also dispensed at community pharmacies. Only four local pharmacies have so far been approved to take part in the supervised methadone scheme. There were 620 episodes of care at our service between 3 April 2001 and 31 April 2002, including 304 new assessments. 


\section{Data extraction and analysis}

Patients were excluded if they were on the waiting list,

original papers

not receiving controlled drugs or on the structured detoxification programme. Data were extracted from the following three electronic databases: (i) the patient registration database, covering 19 items including basic demographic information, drug use, service allocated and date of allocation; (ii) the prescribing software (Advantage-Altrix), which produces patients' prescriptions; and (iii) a database of urine drug screens for the last 7 months (provided by the Department of Chemical Pathology at the Royal Free Hospital). Anonymised data were collated and entered onto the Statistical Package for the Social Sciences. Eleven variables were used: age, gender, prescribed opioid, dose, formulation, frequency of pick-up, supervised consumption, duration of current treatment episode, number of urine drug screens in the past 7 months, proportion of urine screens positive for non-prescribed opiates and treatment programme (slow reduction or maintenance). Slow reduction was empirically defined as any methadone regimen not forming part of the structured detoxification programme, in which there had been two or more successive reductions in dose since January 2000 (when the prescribing database began). All other non-reducing regimens were considered as maintenance.

The $t$-test or one-way analysis of variance were used to compare the means between groups when data followed a normal or near-normal distribution. Categorical data were analysed using the $\chi^{2}$ test. Parametric but highly-skewed data were analysed using the Mann-Whitney U or Kruskal-Wallis tests. Pearson's correlation was used to test the association between two variables. To compare the proportion of urines positive for non-prescribed opiates between maintenance patients on different methadone formulations, a paired analysis of matched cases was used with matching on gender, age, methadone dose and duration of treatment. The paired Wilcoxon signed ranks test was used because of the asymmetric distribution of this variable.

\section{Findings}

During the study period, 174 patients were receiving a prescription for opioids. The characteristics of these patients are shown in Table 1. Of the 169 patients on methadone, 33 were on a slow reduction regimen and the rest on maintenance. There were no statistically significant differences in age or gender distribution between patients on methadone maintenance and slow reduction, and they had been in treatment for similar lengths of time (means=59.5 and 53.5 months, respectively). The slow reduction group had a lower mean proportion of urines positive for non-prescribed opiates compared to the maintenance group ( 0.47 v. 0.54 , respectively), despite being on lower doses of methadone ( mean $=36.9 \mathrm{mg}, \mathrm{SD}=19.5$, range $=8-70 \mathrm{mg}$ ). In Table 2, the prescribing characteristics of all patients on long-term methadone and those specifically on methadone maintenance are compared with data from the south east
Table 1. Characteristics of opioid prescribed patients from an inner London drug service $(n=174)$

\begin{tabular}{|c|c|c|}
\hline Variable & Number & Percentage \\
\hline Mean age - years & 41.8 & - \\
\hline (SD, range) & $(7.54,24.6$ to 61.4$)$ & \\
\hline \multicolumn{3}{|l|}{ Gender: } \\
\hline Male & 118 & 67.8 \\
\hline Female & 56 & 32.2 \\
\hline \multicolumn{3}{|l|}{ Prescribed opioid: } \\
\hline Methadone & 169 & 97.1 \\
\hline Dihydrocodeine & 2 & 1.1 \\
\hline Buprenorphine & 2 & 0.6 \\
\hline Codeine & 1 & 0.6 \\
\hline Naltrexone & 1 & 0.6 \\
\hline \multicolumn{3}{|l|}{ Methadone formulation: } \\
\hline Mixture & 92 & 54.4 \\
\hline Mixture (sugar free) & 38 & 22.5 \\
\hline Tablets & 28 & 16.6 \\
\hline Ampoules & 3 & 1.8 \\
\hline Ampoules+mixture & 7 & 4.1 \\
\hline Tables+mixture & 1 & 0.6 \\
\hline \multicolumn{3}{|l|}{ Methadone regimen: } \\
\hline Maintenance & 136 & 80.5 \\
\hline Slow reduction & 33 & 19.5 \\
\hline \multicolumn{3}{|l|}{ Methadone pick-up: } \\
\hline Daily & 95 & 56.2 \\
\hline $3 x$ weekly & 25 & 14.8 \\
\hline 2x weekly & 19 & 11.2 \\
\hline Weekly & 30 & 17.8 \\
\hline Supervised consumption & 4 & 2.3 \\
\hline $\begin{array}{c}\text { Duration of treatment - } \\
\text { months (SD, range) }\end{array}$ & $\begin{array}{l}58.3 \\
(43.1,0.46 \text { to } 138.0\end{array}$ & - \\
\hline $\begin{array}{l}\text { Mean number of drug } \\
\text { screens in past } 7 \text { months }\end{array}$ & 2.7 & - \\
\hline $\begin{array}{l}\text { Mean proportion of urine } \\
\text { screens positive for } \\
\text { non-prescribed opiates }\end{array}$ & 0.53 & - \\
\hline
\end{tabular}

$\dagger 22$ patients had no urine screens during this period

England pharmacy survey (Strang \& Sheridan, 1998). Because Strang and Sheridan's (1998) survey was unable to distinguish between maintenance and reduction prescriptions, the most appropriate comparison is with the 'all methadone' column.

The proportion of urines positive for non-prescribed opiates was inversely correlated with methadone dose $(-0.26, P=0.004)$ and duration of current treatment episode $(-0.31, P=0.001)$.

Patients receiving methadone ampoules had the lowest proportion of urines positive for illicit opiates, followed by those on tablets and then those on mixture. However, patients on tablets and ampoules were receiving higher doses of methadone. To investigate whether the lower level of illicit opiate use was bestexplained by methadone dose or formulation, a paired analysis of patients on methadone tablets with those on mixture was performed with matching on gender, age, methadone dose and duration of treatment. As some patients had no urine results, there were only 19 pairs in this analysis. The proportion of urines positive for illicit opiates was slightly lower in the tablet (0.40) compared 
Table 2. Prescribing characteristics of patients on methadone maintenance, all long-term methadone patients and Strang \& Sheridan's (1998) pharmacy survey

\begin{tabular}{|c|c|c|c|}
\hline \multirow[b]{2}{*}{ Variable } & \multicolumn{3}{|l|}{ Numbers (\%) } \\
\hline & Maintenance only & All methadone & Strang \& Sheridan, 1998 \\
\hline \multicolumn{4}{|l|}{ Methadone formulation: } \\
\hline Mixture & $102(75)$ & $130(76.9)$ & $709(82.3)$ \\
\hline Tablets & $24(17.6)$ & $29(17.2)$ & $82(9.5)$ \\
\hline Ampoules & $10(7.4)$ & $10(5.9)$ & $70(8.1)$ \\
\hline Mean dose - mg & 65.8 & 60.2 & 51.0 \\
\hline $\mathrm{SD}$, range & $31.2,25-200$ & $31.4,8-200$ & $35.8,-$ \\
\hline Median dose - mg & 60 & 60 & 45 \\
\hline (Interquartile range) & $45-80$ & $40-70$ & $30-60$ \\
\hline Patients in 50 to $100 \mathrm{mg}$ range & $81(59.5)$ & $92(54)$ & $253(44.3)$ \\
\hline \multicolumn{4}{|l|}{ Mean dose by formulation - mg: } \\
\hline Mixture & 57.4 & 52.7 & 46.6 \\
\hline Tablets & 81.8 & 75.3 & 53.7 \\
\hline Ampoules & $113.0^{\dagger}$ & 113.0 & 94.2 \\
\hline \multicolumn{4}{|c|}{ Mean proportion of urines positive for opiates by formulation*: } \\
\hline Mixture & 0.63 & 0.59 & - \\
\hline Tablets & 0.38 & 0.42 & - \\
\hline Ampoules & $0.12 *$ & 0.12 & - \\
\hline \multicolumn{4}{|c|}{ *No urine results for 18 patients on maintenance and 22 of all methadone prescribed. } \\
\hline \multicolumn{4}{|c|}{ †One-way analysis of variance (ANOVA), $F=24.8, P<0.001$. } \\
\hline Kruskal-Wallis ANOVA, $X^{2}=14.8$, d.f.- $2, P=0.01$. & & & \\
\hline
\end{tabular}

with the mixture group (0.54). However, this difference was not statistically significant $(P=0.36)$. Patients on methadone ampoules were not included in this analysis due to insufficient numbers.

\section{Discussion}

Although other UK drug services must have surveyed their methadone prescribing, we have been unable to find any published studies on either Medline or EMBASE. In this study, we have been able to focus on patients in methadone maintenance and have shown that the mean dose is $65.8 \mathrm{mg}$, with $67.7 \%$ of patients taking $50 \mathrm{mg}$ or more. These figures are encouraging, but still suggest that a minority of patients are on a sub-therapeutic dose. There may be good clinical reasons why some patients are on lower doses, such as a low level of dependency, and without more detailed information, generalisations about under-treatment may be premature. However, the inverse relationship between methadone dose and the proportion of urines positive for non-prescribed opiates, a measure of treatment compliance, gives some support to the under-treatment hypothesis. Other areas in the UK may not have the same level of service as that found in Camden and this too may influence the level of methadone prescribing.

The proportion of patients on methadone tablets (17.2\%) was much higher than in Strang and Sheridan's (1998) survey (9.5\%). The reasons for this are unclear. A previous prescribing policy in operation at this service seems to have allowed long-term compliant patients to move onto methadone tablets, if they were no longer injecting. A more restrictive policy was introduced in early
2000, bringing prescription into line with the Department of Health's Clinical Guidelines (Department of Health, 1999). Patients on combination therapy who are HIVpositive are often prescribed methadone tablets because they complain that mixture causes nausea. Since the change in policy, the number of patients receiving methadone tablets has fallen from 44 to 28 . The percentage of patients receiving methadone ampoules is lower (5.9\%) than Strang and Sheridan's (1998) figure (8.1\%). Again, the stricter prescribing policy introduced in 2000 led to the number of patients on ampoules falling from 16 to 10 .

Initial analysis suggested that patients on methadone ampoules or tablets were less likely to use illicit opiates than those taking mixture. However, when matched for gender, age, methadone dose and duration of treatment, drug formulation no longer had an independent effect on illicit drug use.

The inverse relationship between illicit heroin use and length of time in treatment is encouraging, suggesting that patients continue to improve and reduce their drug use over time. There was also an inverse relationship between methadone dose and the proportion of urines positive for illicit opiates, though the correlation was not strong. Two factors are likely to influence this relationship: (i) whether all the methadone prescribed is being taken and (ii) individual variation in the rate of methadone metabolism. Supervised methadone consumption has been advocated in an attempt to reduce the diversion of prescribed methadone onto the black market. In North Camden, we are still at an early stage of implementing supervised consumption in local pharmacies. We are also investigating the cost-benefit of having an on-site pharmacy, which would allow us to supervise 
more prescribed patients. The second factor in the equation is the rate at which methadone is metabolised. original Studies suggest that there is considerable individual papers variation, due to different levels of activity of the cytochrome P450 enzymes (Eap et al, 1998). We argue that monitoring serum methadone levels is a better way of determining methadone dose than using the arbitrary maximum doses set by many clinics. This is not a routine test in the UK and could have considerable costs. However, if its use was restricted to patients who persistently use heroin in addition to their methadone, to investigate the possibility of a pharmacokinetic explanation, the cost would be less prohibitive.

Looking at methadone dose and urine drug screens in isolation gives limited information on the multifaceted nature of treatment outcome. Consequently, we plan to do a larger and more detailed survey of patients on methadone maitenance, in the whole of Camden and Islington, to gain a better perspective of our prescribing practices and the clinical effectiveness of this intervention. The present study has acted as a useful pilot exercise, to identify problems that might arise with a larger survey.

\section{Declaration of interest}

John Dunn has received travel expenses and an honorarium for attending a meeting organised by Napp Pharmaceuticals, who produce Subsitol (slow release morphine).

\section{Acknowledgements}

I would like to thank Doborah Zador for her helpful comments and both Brendon Gregory and Martin Fajimi for their assistance with the databases.

\section{References}

DEPARTMENT OF HEALTH (1996) The Task Force to Review Services for Drug Misusers. London: HMSO.

- (1998) Statistics from the Regiona Drug Misuse Databases, for the six months ending 1998. http:// www.doh.gov.uk/public/ drugmisuse.htm

- (1999) Drug misuse and dependence - guidelines on clinical management. http:// www.doh.gov.uk/drugdep.htm

EAP, C. B., BERTSCHY, G., BAUMANN P., et al (1998) High interindividual variability of methadone enantiomer blood levels to dose ratios. Archives of General Psychiatry, 55, 89-90.

FARRELL, M.,WARE, J., MATTICK, R., et al (1994) Methadone maintenance treatment in opiate dependence: a review. British Medical Journal, 309 997-2001.

GOSSOP, M., MARSDEN, J., STEWART, D., et al (1999) Methadone treatment practices and outcome for opiate addicts treated in drug clinics and in general practice: results from the National Treatment Outcome Research Study. British Journal of General Practice, 49, 31-24.

STRANG, J. \& SHERIDAN, J. (1998) Effect of government recommendations on methadone prescribing in south east England: a comparison of 1995 and 1997 surveys. BMJ, 317, 1489-1490.

—\& - (2001) Methadone prescribing to opiate addicts by private doctors: comparison with NHS practice in south east England. Addiction, 96, 567-576.

-, - \& BARBER, N. (1996) Prescribing injectable and oral methadone to opiate addicts: results from the 1995 national postal survey of community pharmacies in England and Wales. BMJ, 313 , $270-272$

John Dunn Senior Lecturer in Substance Misuse and Honorary Consultant Psychiatrist, Department of Psychiatry and Behavioural Sciences, Royal Free Hospital, Pond Street, London NW3 20G 